\title{
Expression of the Epstein-Barr virus 138-kDa early protein in Escherichia coli for the use as antigen in diagnostic tests
}

(Recombinant DNA; nasopharyngeal carcinoma; pUC plasmid vectors; fusion proteins; prediction of antigenic sites)

\author{
M. Motz, J. Fan, R. Seibl, W. Jilg and H. Wolf* \\ Max von Pettenkofer-Institut, University of Munich, Pettenkoferstrasse 9a, 8000 Munich 2 (F.R.G.) Tel. (089)53932I
}

(Received August, 15th, 1985)

(Revision received February 3rd, 1986)

(Accepted February 4th, 1986)

\section{SUMMARY}

We have attempted to produce the 138-kDa early protein (ep138) of Epstein-Barr virus (EBV) in Escherichia coli. This protein was found, by immunoprecipitation, to be a clinically relevant antigen, especially for the determination of the IgA-titer in patients with nasopharyngeal carcinoma (NPC). Since the expression of the entire ep 138 coding region was unsuccessful, we synthesized only the antigenic parts of this protein. Potential antigenic sites were predicted from the amino acid sequence by combining values for hydrophilicity with calculated estimates of the secondary structure. The two predicted fragments were found to be antigenic, but only one of them was stably expressed in $E$. coli as a non-fusion protein. This stable protein fragment was, in turn, able to stabilize the second antigenic fragment forming an autologous fusion protein, consisting exclusively of EBV-derived sequences. The resulting product reacts particularly well with IgA antibodies of NPC patients indicating its diagnostic value for NPC. * To whom correspondence and reprint requests should be ad-
dressed.

Abbreviations: aa, amino acid(s); Ap, ampicillin; bp, base pair(s); $\Delta$, deletion; EA, early antigen; ELISA, enzyme-linked immuno-sorbent assay; EBV, Epstein-Barr virus; ep138, 138$\mathrm{kDa}$ early protein of EBV; FR. followed by roman numbers, DNA-fragment(s); $\beta \mathrm{Gal}, \beta$-galactosidase; Ig, immunoglobulin; IPTG, isopropyl- $\beta$-D-thiogalactoside; lac $Z \alpha$, part of lac $Z$ coding for $\alpha$ peptide; LB, Luria broth; NPC, nasopharyngeal carcinoma; $A$, absorbance at $600 \mathrm{~nm}$; oligodnt, oligodeoxynucleotide; $\mathrm{ORF}$, open reading frame; PA, polyacrylamide; PAGF, PA gel electrophoresis; SDS, sodium dodecyl sulfate; VCA, virus capsid antigen; XGal, 5-bromo-4-chloro-indolyl- $\beta$-D-galactoside; : :, novel joint.

\section{INTRODUCTION}

Epstein-Barr virus (EBV) can cause infectious mononucleosis after primary infection and is strongly linked to the undifferentiated form of NPC and as an etiologic factor to African Burkitt's lymphoma. In some areas of Southern China, Singapore and Malaysia, NPC is the most frequent neoplasia with an incidence of up to 40 cases per 100000 inhabitants per year. Early detection is particularly important because this tumor responds very well to radiotherapy in the early stages (survival rates up to $93 \%$ in stage I and $75 \%$ in stage II) and dramatically less in 
more advanced stages. Although EBV DNA can be demonstrated in tumor cells of all NPC biopsies tested, this approach is not feasible for mass screening for an early detection of this tumor. Prior to the onset of tumor formation elevated titers of IgG and $\operatorname{IgA}$ antibodies to the viral capsid antigens and early antigens have been described for NPC patients. Field studies have already demonstrated the value of serological screening (Zeng et al., 1985). (For references on the EBV-related diseases and diagnosis see Simons and Shanmugaratnam, 1982.)

Mass screening of the high-risk groups would be possible if inexpensive and automat-readable tests were available. When partially purified antigens from EBV-producing cell cultures are used, tests are prone to background reactions and are expensive. Therefore we decided to produce an EBV-related antigen by gene technological methods and use it in an ELISA. This should result in higher sensitivity and provide a low-cost, rapid screening system for the early detection of NPC and also for the diagnosis of other EBV-related diseases.

We describe approaches for the expression of ep 138, which belongs to the early antigen group in the lytic EBV infection. This protein is known to be a major DNA-binding protein which shares homologies to the ICP8 from HSV1 (D. McGeoch, R.S. and H.W., unpublished). We selected the ep138 for several reasons: after induction of EBV-infected cells the ep138 is one of the most abundant early proteins (Bayliss and Wolf, 1981); sera from different NPC-patients contain antibodies against this protein (Wolf et al., 1984); the coding region was located in the BamHI-A fragment in an area with appropriate reading frames (Seibl and Wolf, 1985).

\section{MATERIALS AND METHODS}

\section{(a) Bacterial strains and plasmids}

The BamHI-A fragment of EBV containing the region coding for ep 138, cloned into the $B a m H I$ site of pBR322, was obtained from J. Skare (1980). For cloning and expression procedures $E$. coli strain JM83 \{ara, $\triangle($ lac-proAB $)$, strA, lac $Z \Delta \mathrm{M} 15, \phi 80\}$, and JM109 \{recA1, endA1, gyrA 96, thi, hsdR 17, supE $44, \operatorname{relA} 1, \lambda^{-}, \Delta($ lac-proAB $),\left[\mathrm{F}^{\prime}, \operatorname{traD} 36\right.$,
$\operatorname{proA}^{+} \boldsymbol{B}^{+}$, lacI $\left.\left.^{\mathrm{q}} \mathrm{Z} \Delta \mathrm{M} 15\right]\right\}$ (Yanisch-Perron, et al., 1985) and plasmids pUC8, pUC9, pUC13 (Vieira and Messing, 1982), pEA305 (Amann et al., 1983), pKK240-11 (Amann and Brosius, 1985), pUR278, pUR288 (Rüther and Müller-Hill, 1983) and pINIII$\Lambda 1$ (Masui et al., 1984) were used.

\section{(b) DNA-sequences and computer programs}

The sequence of the Bam HI-A fragment was obtained from B. Barrell (Baer et al., 1984) prior to publication. For searching restriction enzyme sites, reading frames and maps the UWGCG programs (Devereux et al., 1984) were used.

The program for the prediction of antigenic sites by calculating the secondary structures superimposed with values for hydrophilicity was developed in our laboratory for the VAX750 on the basis of a program written by E. Golub (Cohen et al., 1984). Our program was written to function as a subprogram of the UWGCG software and can therefore directly use sequences from the major protein or nucleic acid libraries.

\section{(c) Induction and analysis of expression products}

Overnight cultures of clones containing the desired plasmids were grown in LB-medium containing $50 \mu \mathrm{g} \mathrm{Ap} / \mathrm{ml}$. They were diluted to an $A=0.3$; when the $A$ reached 0.7, IPTG was added to give a final concentration of $1 \mathrm{mM}$ and the cultures were incubated for another $2 \mathrm{~h}$. Cell pellets from $1.5 \mathrm{ml}$ culture were lysed in $150 \mu \mathrm{l}$ of sample buffer (Laemmli, 1970), boiled for $5 \mathrm{~min}$ and $10-25 \mu \mathrm{l}$ of the lysate were separated by SDS-PAGE and evaluated after staining with Coomassie blue.

\section{(d) Detection of EBV-related antigenic proteins}

After SDS-PAGE the proteins of the bacterial lysates were transferred onto nitrocellulose (Burnette, 1981). The nitrocellulose filter was preadsorbed for $2 \mathrm{~h}$ with a modified $5 \times$ Denhardt's solution (Denhardt, 1966) supplemented with $0.1 \%$ Nonidet P-40, $1.5 \%$ bovine serum albumin, $170 \mathrm{mM}$ borate, $150 \mathrm{mM} \mathrm{NaCl}, 0.25 \%$ gelatine and $0.04 \% \mathrm{NaN}_{3}$ (Cohen et al., 1984) and incubated overnight at room temperature with a $1: 50$ diluted high-titered NPC serum pool (EA 1: 1200, VCA $1: 6600$ ) or individu- 
al sera which were previously preadsorbed with bacterial lysates. After washing with gelatine buffer (50 mM Tris $\cdot \mathrm{HCl}, \mathrm{pH} 7.5,5 \mathrm{mM} \mathrm{Na} \mathrm{Na}_{2} \cdot$ EDTA, $150 \mathrm{mM} \mathrm{NaCl}, 0.25 \%$ gelatine, $0.5 \%$ Triton X-100, $0.1 \%$ SDS) the bound antibodies were incubated with peroxidase-conjugated anti-human IgG or IgA rabbit antibodies (Dako) and stained with $0.01 \%$ $\mathrm{H}_{2} \mathrm{O}_{2}$ and $0.5 \mathrm{mg} / \mathrm{ml}$ diaminobenzidine (Sigma).

\section{RESULTS AND DISCUSSION}

\section{(a) Localization of the ORF coding for ep138}

According to the mapping data obtained by hybrid-selected translation of mRNA from induced P3HRl cells probed with cloned Bam HI fragments, the coding region for the ep 138 is located in the Bam HI-A fragment at the right end of the viral genome (Seibl and Wolf, 1985). Three leftward oriented large ORFs can be identified from the sequence data. Although splice events cannot be excluded, an ORF at the right end of the Bam HI-A (BALF2 according to Baer et al., 1984) was the right size to encode the ep138. To test our assumption, we inserted a $3.0-\mathrm{kb}$ XhoI fragment spanning this ORF into pUC8 and used the resulting plasmid, pUC635, as a probe for a hybrid-selected translation of mRNA from induced P3HR1 cells. Fig. 1 gives an overview on the localization of ep138-encoding sequences used for the engineering to obtain pUC635 and other clones described in the following. Fig. 2 shows that ep138 is encoded by this ORF, with 1128 aa and a calculated $M_{\mathrm{r}}$ of 123027 .

\section{(b) Synthesis of large segments of ep138}

We used the pUC plasmid vectors, which have previously been used to express eukaryotic proteins in $E$. coli (e.g., Guise et al., 1985) or vectors with tac promoters (DeBoer et al., 1983). In addition to pUC635 (also used for mapping), three other plasmids with large fragments of the ep 138 coding region were derived (pUC924, pMF924 and pKK378; Fig. 1; vectors and details of construction see legend Fig. 3) and tested for production of an EBV-related antigen.

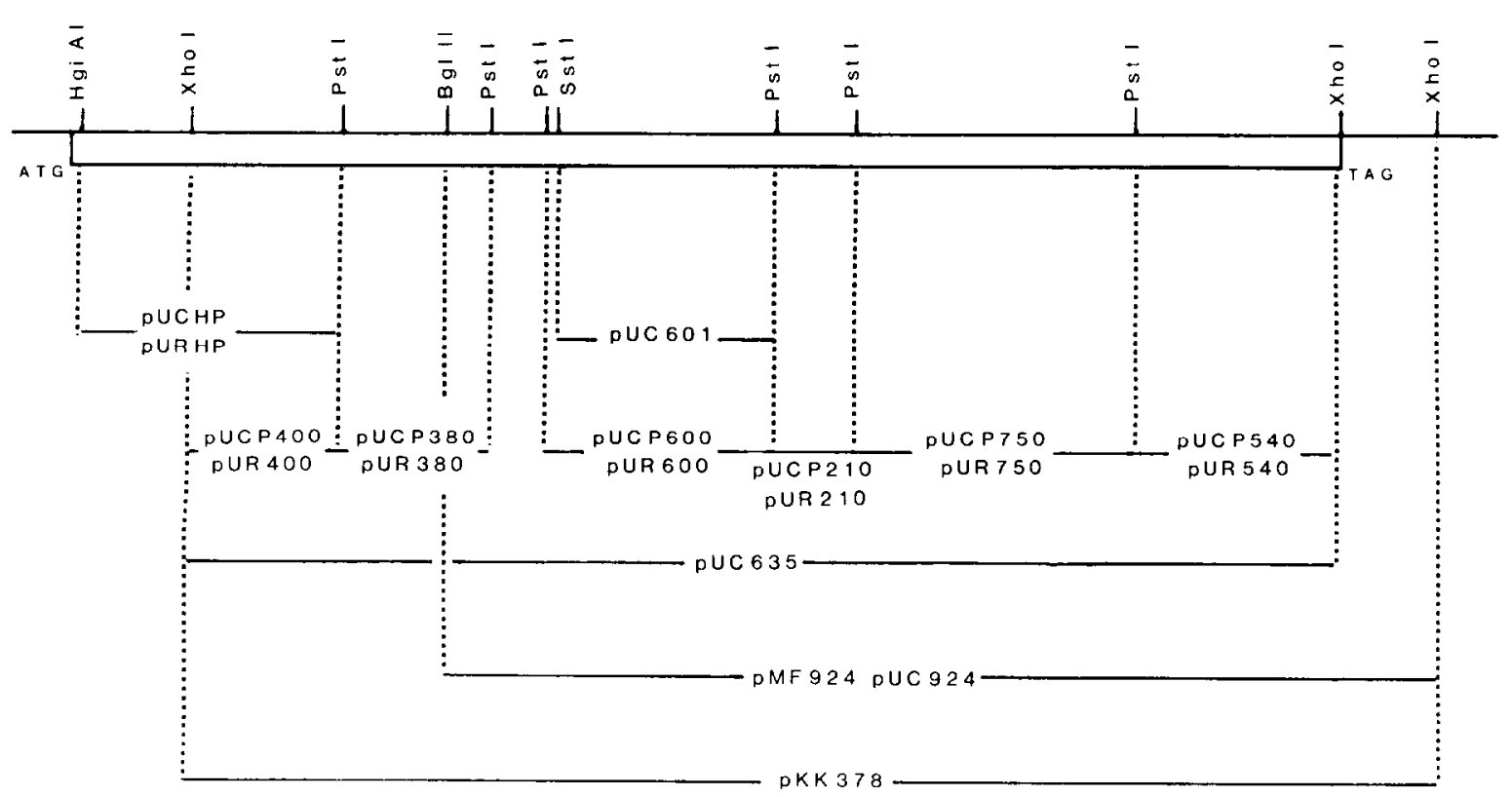

Fig. 1. The ORF encoding ep138 of EBV strain B95-8 (open bar) and localization of restriction sites used for the construction of subclones indicated in the lower part. The HgiAI site at the N-terminus cleaves in the sequence encoding aa No. 3. The second XhoI site is located two aa upstream of the stop codon of ep138. The third XhoI site is 250 bp downstrcam. pUC635 (used for hybrid-selected translation), pKK378, pUC924 and pMF924 encode large segments of ep138. Their construction is given in legend of Fig. 3. The engineering of the small fragments which yield the other indicated pUC and pUR plasmid constructs is explained in legends of Figs. 5 and 6. 


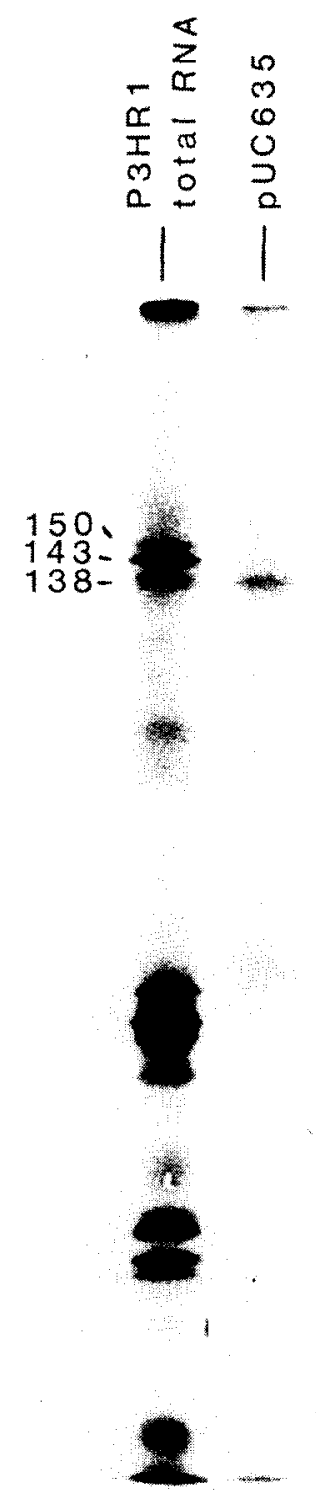

Fig. 2. In vitro translation of mRNA from induced P3HR1 cells after hybrid selection with pUC635 (right lane) and unselected total RNA as control (left lane). The position of ep138 (138 kDa) and of two other proteins, which belong to the VCA group (Bayliss and Wolf, 1981), are indicated (sizes in $\mathrm{kDa}$ ). To select mRNA, $8 \mu \mathrm{g}$ of pUC635 was sheared by sonication and spotted to $5 \times 5 \mathrm{~mm}$ nitrocellulose filter. After washing and baking at $80^{\circ} \mathrm{C}$ for $2 \mathrm{~h}, 100 \mu \mathrm{g}$ RNA from induced P3HR 1 cells (induction of P3HR1 with $40 \mathrm{ng} / \mathrm{ml}$ phorbol-12-myristate-13-acctatc and $3 \mathrm{mM}$ butyric acid for three days) was hybridized to the filter. Bound mRNA was eluted by boiling, precipitated with ethanol and translated with a mRNA dependent rabbit reticulocyte lysate in the presence of $\left[{ }^{35} \mathrm{~S}\right]$ methionine as described earlier (Seibl and Wolf, 1985). For translation of unselected RNA, $7 \mu \mathrm{g}$ were added to the translation assay. The labeled proteins were mixed with immunoprecipitation buffer $(1 \%$ Triton X-100, $0.1 \%$ SDS, $0.137 \mathrm{M} \mathrm{NaCl}, 1 \mathrm{mM} \mathrm{CaCl}, 1 \mathrm{mM} \mathrm{MgCl}_{2}, 10 \%$ glycerol,
All the expression-plasmid-produced segments of ep 138 were in the expected $M_{\mathrm{r}}$ range, but the yield was low and varied widely. The fusion proteins encoded by the constructs pUC635 and pMF924 seem to give better expression in a more stable fashion than the non-fusion proteins from pUC924 and pKK 378. The antigen yield from pUC635, which gave the highest expression, was far too low for large-scale production. A reproducible expression was only possible with the lac-repressor protein overproducer $r e c A^{-}$strain JM109. Apparently the ep138 is toxic to the bacterial cells, perhaps, due to its proposed DNA-binding capacity (Roubal et al., 1981). A similar result was obtained with the expression of ICP8 of HSV1 (Pearson et al., 1985), which seems to have the same DNA-binding function and shares homologies to the protein sequence of ep 138 .

\section{(c) Computer-predicted localization of antigenic sites}

In the ELISA the presence of antigenic sites is important and not the entire protein. Since the expression of large parts of ep 138 is difficult and inefficient, we decided to express only small antigenic peptides from ep138. Antigenic sites are often assumed to be in hydrophilic areas. The examination of hydrophilicity plots, however, did not allow the identification of appropriate sites for a promising sub-genomic expression cloning. Based on the assumption that antigenic sites are mainly located within hydrophilic $\beta$-turns, we used a computer program, which superimposes the data for hydrophilicity (Hopp and Woods, 1981) upon the secondary structures predicted from the algorithms of Chou and Fasman (1974a,b) and Argos et al. (1978) (Fig. 4). A similar program was successfully used for predictions of antigenic sites in $\mathrm{gpB}$ from IISV1 (Cohen et al., 1984). Our program was tested for its validity with the polio virus VP1, where the antigenic sites were mapped by synthetic peptides or monoclo-

$20 \mathrm{mM}$ Tris $\cdot \mathrm{HCl}, \mathrm{pH} 9.0,0.01 \% \mathrm{NaN}_{3}$ and $1 \mathrm{mM}$ phenylmethyl-sulfonyl fluoride) and incubated with $5 \mu$ leach of the NPC serum pool (preadsorbed with a protein extract from EBV-negative BJA cells). Immune complexes were bound to protein $\mathrm{A}$ sepharose, washed, eluted by boiling and fractionated by SDS $-12 \%$ PAGE. The gel was dried and exposed to a $\mathrm{X}$-ray film. 


$\begin{array}{lllll} & 0 & 0 & 0 & 10 \\ 0 & N & 0 & 0 & 0 \\ 0 & 0 & 0 & 0 & 0 \\ 0 & 0 & x & 11 & 0 \\ 0 & 0 & x & \sum_{0} & 0 \\ 1 & 1 & 0 & 0 & 0\end{array}$

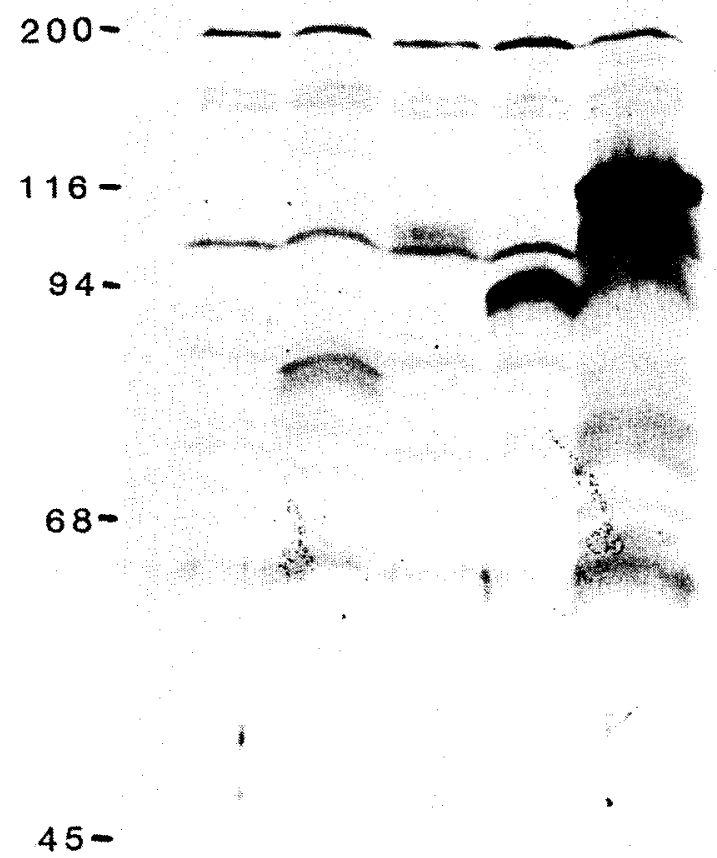

Fig. 3. Expression of major fragments of ep138 in E. coli. The proteins of IPTG-induced JM 109 cells carrying plasmids indicated on top were separated on a SDS-10\% PA gel and transferred to nitrocellulose. EBV-related proteins were visualized by immunostaining with the NPC serum pool; human sera show a moderate reaction with $E$. coli proteins which results in background bands. In the left lane proteins from cells carrying pUC8 were applied as a control. Sizes on the left margin are in $\mathrm{kDa}$. The DNA fragments used for the construction of these clones and their location on the ep138 encoding region is shown in Fig. 1. pUC924 contains the $2.6-\mathrm{kb}$ fragment from the $B g / \mathrm{II}$ site to the third Xhol site, the translational stop codon from ep 138 should be used and the resulting non-fusion protein has a size of about $80 \mathrm{kDa}$. The plasmid pMF924 was constructed from pEA305 (Amann et al., 1983) and the same Bglll-XhoI fragment as in pUC924. pEA305 has a tac promotcr followed by the N-terminal part of the $c 1857$-coded $\lambda$ repressor, hence the resulting fusion protein is $17 \mathrm{kDa}$ larger than from pUC924. The plasmid pUC635 has an insert corresponding to aa 108 up to aa 1127 , the a immediately before the stop codon of ep 138 . The $3.05-\mathrm{kb}$ Xho I fragment was inserted into the SalI site of pUC8 and the reading frame of the pUC-encoded $l a c Z \alpha$ fits with the ep138 ORF at the $5^{\prime}$ and the $3^{\prime}$ end. The resulting expression product is a fusion protein with 11 aa at the $\mathrm{N}$-terminus and $11 \mathrm{kDa}$ of the $\operatorname{lac} Z \alpha$. nal antibodies (Jameson et al., 1984). The computer predictions agree very well with the recently determined X-ray crystallographic data (Hogle et al., 1985).

This approach suggested the presence of two major potential antigenic epitopes (Fig. 4), one located around aa 520 (FR.IV) and the other close to the C-terminus of ep138 (FR.VII).

\section{(d) Subcloning and expression as $\beta$ Gal fusion pro- teins of DNA fragments encoding segments of ep138}

To test the computer-aided localization, we examined segments of ep138 for antigenicity. Since most eukaryotic protein segments are degraded immediately after synthesis in bacteria, fusion proteins with the large bacterial $\beta \mathrm{Gal}$ were constructed to protect the ep138 protein segments from proteolysis. The DNA fragments corresponding to the protein segments indicated in Fig. 4 were subcloned from the Bam HI-A fragment and pUC635 and inserted at the $3^{\prime}$ end of the lac $Z$ gene of the pUR-vectors (Ruther and Müller-Hill, 1983). Fig. 5, left panel, shows the expression of the resulting fusion proteins with the various ep 138 segments. The immunostained Western blot, using pooled human sera from NPC patients, allows the identification of antigenic ep 138 segments (Fig. 5, right panel). As predicted by our computer program, only the fusion proteins from clones pUR600 and pUR540 carrying FR.IV and FR.VII, respectively, react as EBV-specific antigens.

\section{(e) Expression of the subfragments in pUC plasmid vectors}

Due to the presence of antibodies in human sera specific for bacterial proteins, the use of $\beta \mathrm{Gal}$ fusion protcins in ELISA may give erroneous results. Therefore, we tested whether the pUC clones used for the construction of the pUR plasmids (see legend Fig. 5) would produce stable products. In these pUC clones the ORFs of the inserts (FR.I-FR.VII) are in

The insert of pKK 378 starts at the same $X$ hoI site and continues to the third XhoI site located 250 bp $3^{\prime}$ of the stop codon. The $3.3-\mathrm{kb}$ fragment was inserted $3^{\prime}$ of the tac promoter and the start codon of pKK240-11. The expression product contains only two bacterial amino acids and the $M_{\mathrm{r}}$ is considerably smaller than in pUC635. 


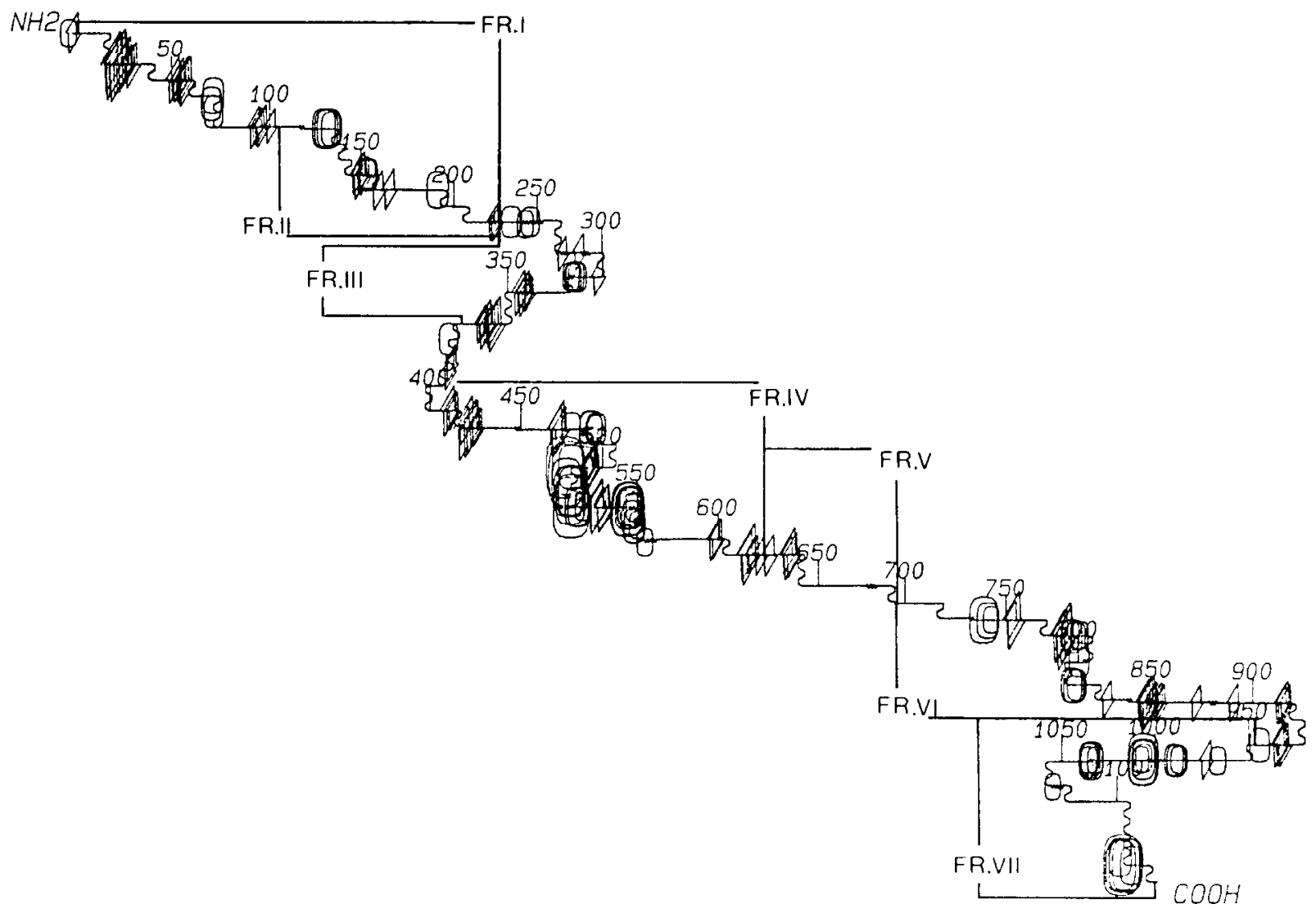

Fig. 4. Computer plot of the predicted secondary structure of ep138 aa sequence. The dark line represents the aa backbone (numbers indicate aa positions) with the probable $\alpha$-helices, $\beta$-sheets, coil-structures (barely discernable in the scale used) and $\beta$-turns (line turn of $180^{\circ}$ ). Hydrophilic areas are given as circles, hydrophobic as diamonds (maximum values from -3 to +3 indicated are aa in stretches with averages over \pm 0.9 , calculated for 7 aa). The DNA fragments FR.I to FRVII used for subcloning and examination for antigenic sites (see legend Fig. 5) encode the indicated protein segments. Strong hydrophilic loop structures can be seen around aa 520 (encoded by FR.IV) and near the N-terminus (FR.VII). In these regions an antigenic reaction could be expected.

frame with the pUC-encoded lac $Z \alpha$ at their $5^{\prime}$ and $3^{\prime}$ ends. Therefore the expression products are fusion proteins with a small $11-\mathrm{kDa} \beta \mathrm{Gal}$ fragment at the C-terminus. Only the plasmid pUCP600, carrying the FR.IV-fragment (Fig. 4), expresses an additional polypeptide of about $32 \mathrm{kDa}$ resulting from transcription and translation of the 600-bp of FR.IV $(21 \mathrm{kDa})$ and the lacZ $\alpha$ (11 kDa) (Fig. 7, pUCP600 lanes, PA gel of the pUC constructs with FR.I,II,III,V,VI and VII not shown). In an immunoblot with the NPC serum pool this protein gives a stronger signal than the corresponding pUR clone, suggesting that the epitope in the large fusion product is partially hidden by the large $\beta \mathrm{Gal}$. The instability of the translation products from pUC vectors carrying the other DNA fragments of the ep 138 coding region is not too surprising since the products are small protein segments which might not fold such that they are protected from proteolytic degradation. When the $E$. coli strain JM83 was transformed with the pUC-derived plasmids, all transformed colonies on agar plates containing XGal and Ap appeared light blue. Strain JM83 does not overproduce the lac repressor and needs the $N$-terminal part of the $\beta \mathrm{Gal}$ encoded by the pUC plasmid for the $\alpha$-complementation of its partially deleted genomic lac $Z$ gene. The light blue color indicates that the ORF of the pUCencoded $l a c Z$ from the initiation codon through the inserted fragment is transcribed and translated. This finding suggests that all subfragments are expressed, but degraded immediately after synthesis. 


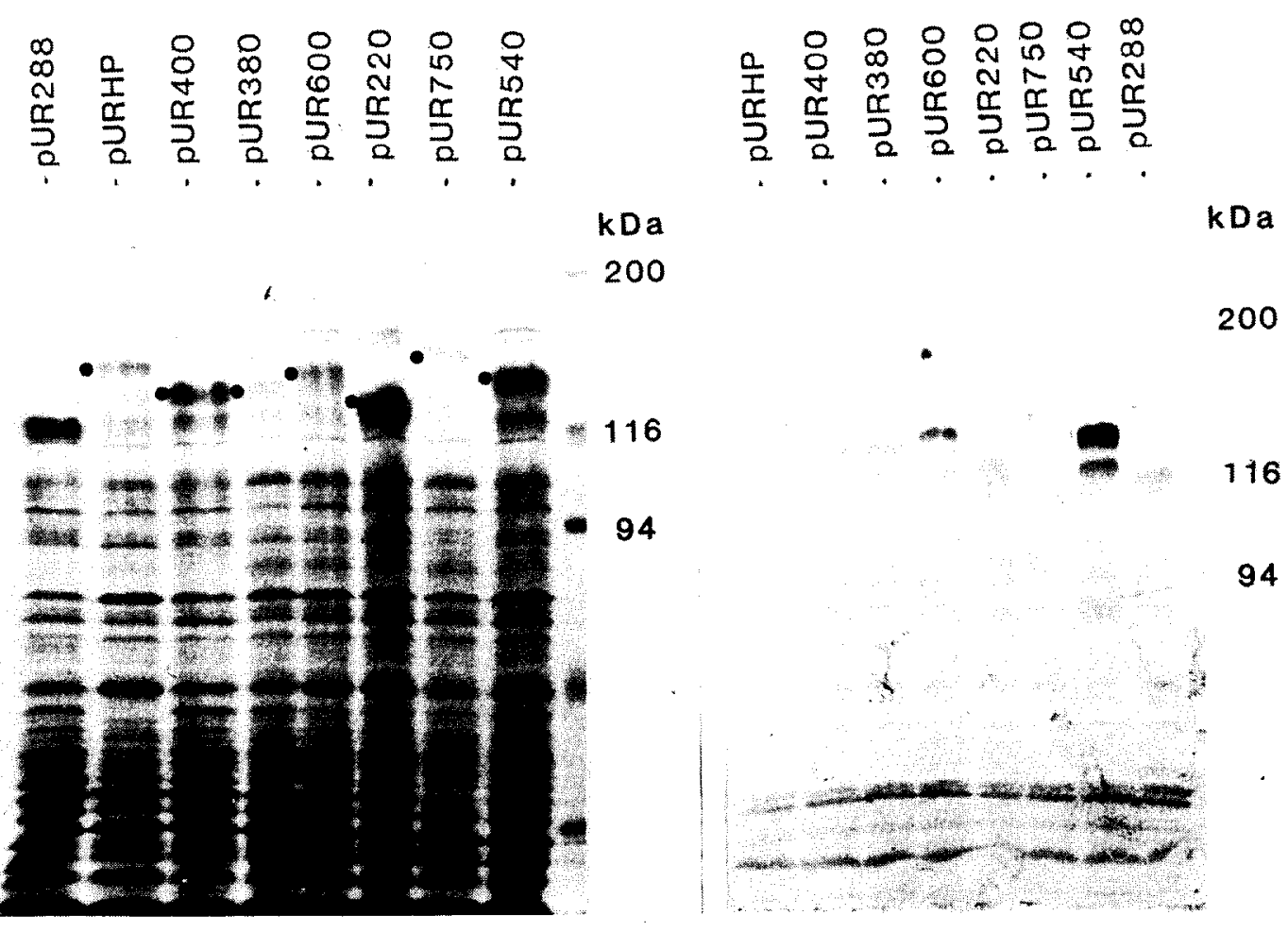

Fig. 5. Expression of ep 138 segments as $\beta$ Gal fusion proteins and localization of antigenic sites. The proteins of the IPTG-induced clones indicated on top of each lane were analysed by SDS-10\% PAGE and Coomassie blue staining (left panel). In comparison to the $\beta$ Gal encoded by pUR288, the $\beta \mathrm{Gal}$ : ep138 fusion proteins (black dots) have an increased $M_{\mathrm{r}}$ depending on the DNA insert size (bp correspond to clone numbers). The right panel shows the same SDS.PA gel after Western blotting and immunostaining with the NPC serum pool. As predicted by the computer drawings (Fig. 4) the fragments FR.IV in pUR600 and FR.VII in pUR540 encode protein segments which were recognized by the human immune system. The HgiAI-Pst I fragment (FR.I, Figs. $1+4$ ) was cloned from Bam HI-A into pUC9 to yield pUCHP, isolated from this plasmid as Eco RI-HindIII fragment and inserted into pINIIIA1. With this procedure a second $B a m \mathrm{HI}$ site (besides the one originated from pUC9) was generated next to the HindIII site. From a resulting clone the FR.I was excised with $B a m H I$ and inserted into pUR288 to yield pURHP. pUR400 carrying FR.II was obtained from pUC635 digested with Pst I, religation (pUCP400) and insertion of FR.II as BamHI-HindIII fragment into pUR288. The constructs pUR380 (FR.III), pUR600 (FR.IV), pUR210 (FR.V), pUR750 (FR.VI) and pUR540 (FR.VII) were achieved by insertion of $P_{s t I}$ fragments of pUC635 into pUC8, isolation of the EBV DNA sequences as BamHI-HindIII fragments and ligation with pUR288.

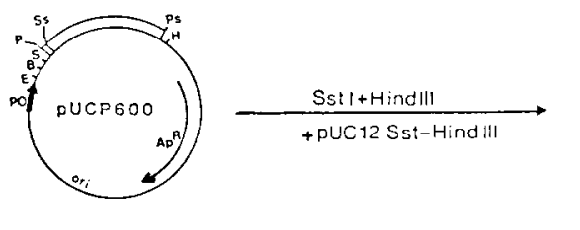

(1)
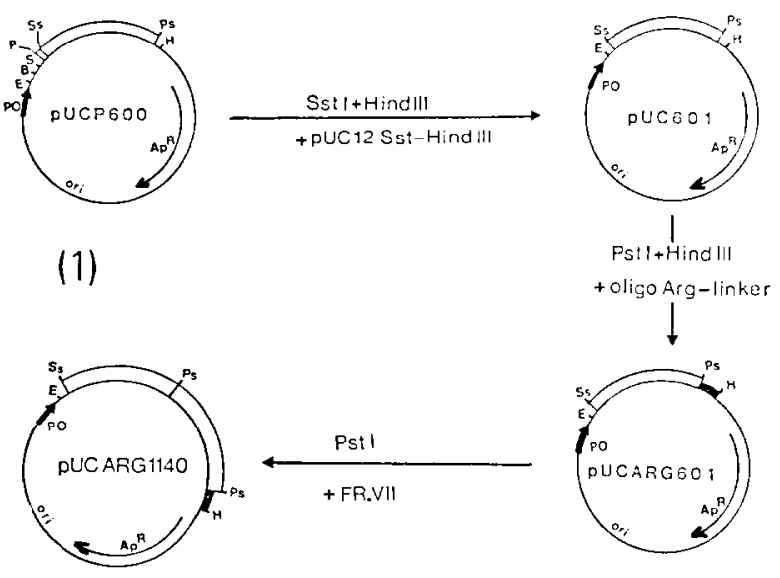

(2)

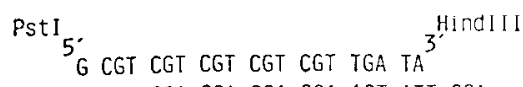
AC GTC GCA GCA GCA GCA GCA ACT ATT CGA Arg Arg Arg Arg arg stop stop
Fig. 6. Construction of the plasmid pUCARG1140 encoding both antigenic sites found by expression as $\beta$ Gal fusion proteins. (1) Scheme of the cloning procedures. Using a $S s t \mathrm{I}$ site which is located 25 bp from the 5' PstI site (Fig. 1), Fr.IV of pUCP600 was isolated as Sst I-HindIII fragment and inserted into pUC12 (pUC601). Between the PstI and HindIII sites of this plasmid the oligodnt [see (2) below] was inserted to yield pUCARG601. The fragment FR.VII encoding the second antigenic site was integrated as $P s t \mathrm{I}$ fragment derived from pUCP540. E, Eco RI; B, BamHI; S, SalI; Ps, PstI; Ss, SstI; H, HindIII; PO and heavy arrow, lacZ UV5 promoter and operator of the pUC plasmids; open segment, ep138 encoding sequences; shaded segment, synthetic oligodnt. (2) Nucleotide sequence of the oligodnt coding for five arginine residucs and two stop codons when inserted into pUC601. The lower strand was synthesized and inserted as single-stranded DNA between the sticky ends of $P_{s t} \mathrm{I}$ and HindIIl via bridge formation, ligation and transformation into $E$. coli JM109. The correct integration was proved through sequence analysis (not shown). 
(f) Combination of the two antigenic sites and insertion of an oligodeoxynucleotide encoding oligoarginine

DNA fragments FR.IV and FR.VII were combined in frame on one plasmid to obtain an ORF encoding both antigenic regions found in ep138. To prevent translation of vector-encoded sequences, a synthetic oligodnt coding for two translational stop codons was inserted at the $3^{\prime}$ end of the ORF. The oligodnt further codes for five arginine residues $5^{\prime}$ of the stop codons. The resulting construct (pUCARG1140) codes for a protein consisting of the two antigenic epitopes with five arginine residues at the C-terminus. The protein segment encoded by FR.VII, which was previously shown to be instable in the pUC expression, is now stabilized by the peptide encoded by FR.IV. The additional arginine residues may be useful for the purification following a procedure of Sassenfeld and Brewer (1984). The sequence of the oligodnt and the construction scheme for pUCARG1140 is given in Fig. 6 and the expression products of the various constructs leading to pUCARG1140 are shown in Fig. 7.

The combination of the two antigenic sites was necessary to cover the spectrum of antibodies directed against ep138, since the immunological reactions differ in the various patients (Fig. 8). Whereas in NPC serum No. 352 the main fraction of the IgG and $\operatorname{IgA}$ antibodies is directed against the epitope encoded by FR.VII, the reaction in NPC serum No. 354 shows the reverse pattern. A representative

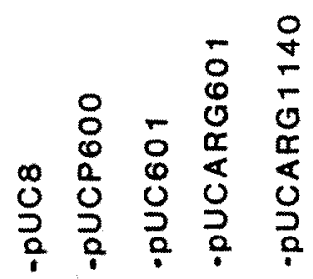

kDa

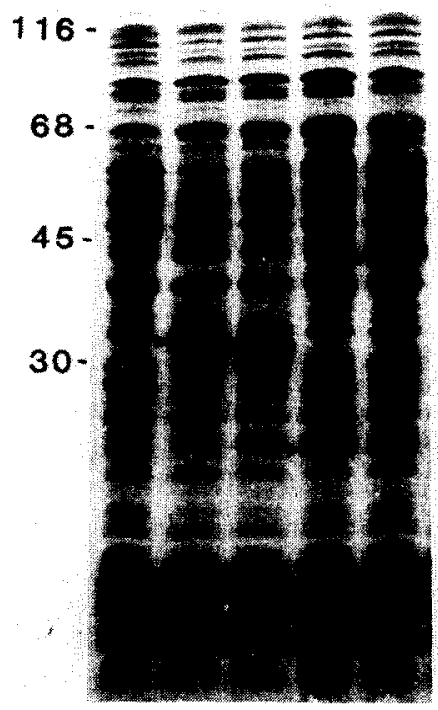

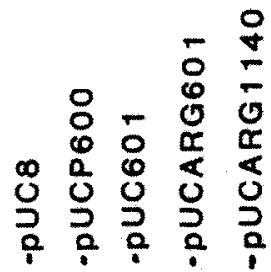

116.

68 .

$45-$

$30^{-}$

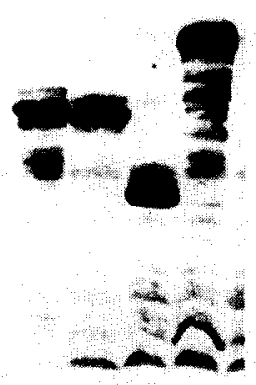

Fig. 7. Expression in pUC plasmids of antigenic segments of ep 138. Proteins of IPTG-induced clones carrying pUC plasmid constructs. described in legend of Fig. 6 and indicated on top, were analysed through SDS-17\% PAGE and Coomassie blue staining (left panel). EBV-related expression products are indicated by arrowheads. The right panel shows the same SDS-PA gel after Western blotting and immunostaining with the NPC serum pool. In comparison to pUCP600, the $M_{\mathrm{r}}$ of the protein encoded by FR.IV is decreased by about $1.5 \mathrm{kDa}$ in pUC601 due to the lack of 14 aa ( 6 aa encoded by the pUC polylinker and 8 aa from the deleted $P s t \mathrm{I}-S s t \mathrm{I}$ sequence in FR.IV). The size of the protein encoded by pUCARG601 is further reduced by about $11 \mathrm{kDa}$ since read-through into the lac $Z \alpha$ of pUC is inhibited by the stop codons inserted with the oligoArg-coding oligodnt. In pUCARG1140 the size increases to about $42 \mathrm{kDa}$ due to the insertion of FR.VII ( $540 \mathrm{bp})$. 


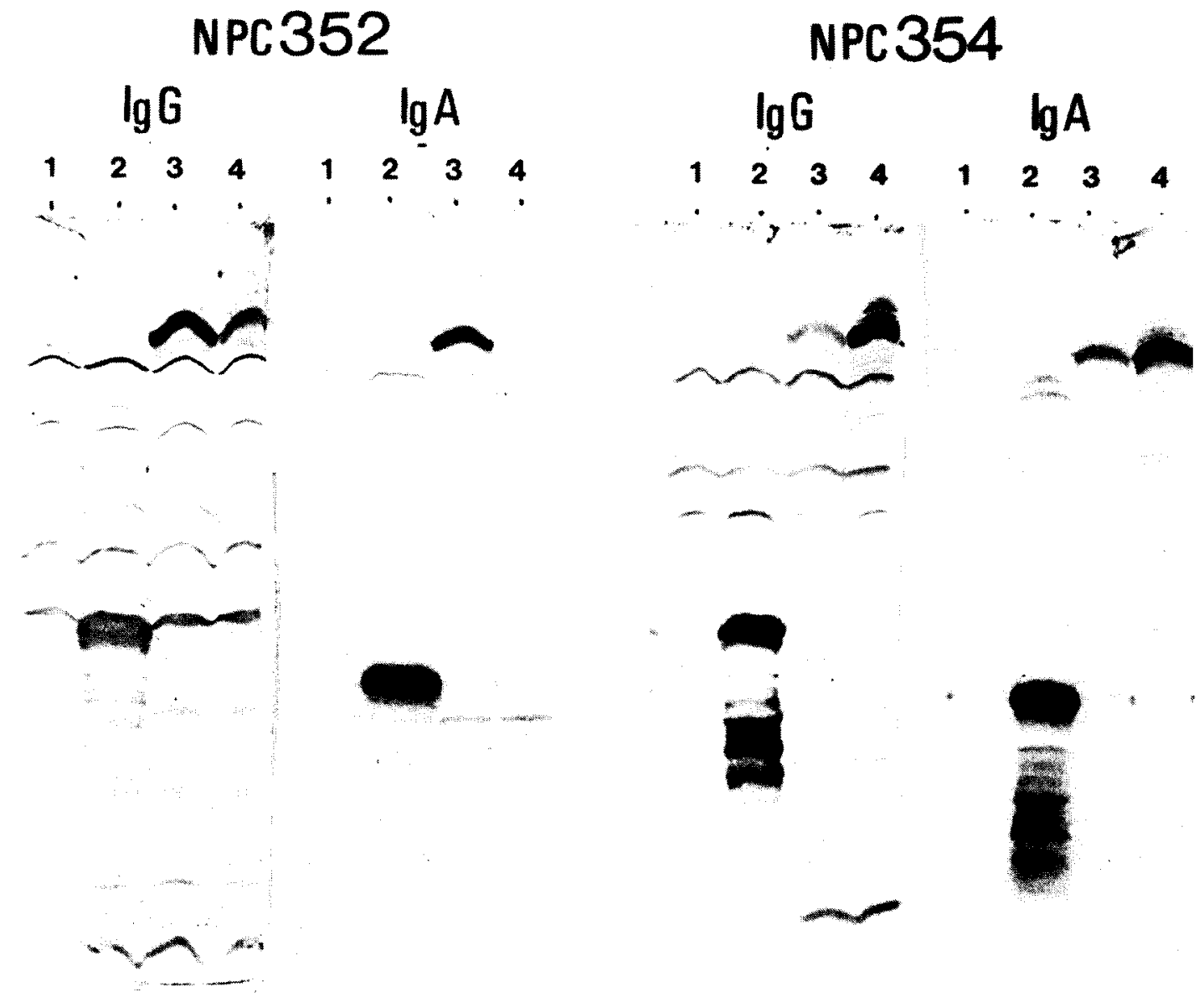

Fig. 8. Distribution and reactivity of the IgG and IgA antibodies of individual NPC sera against the two antigenic regions detected in ep138. Aliquots of IPTG-induced clones were separated through SDS-12\% PAGE and transferred onto nitrocellulose filters. Two individual NPC-sera (Nos. 352 and 354) were incubated with the filters and the IgG and IgA antibodies bound were visualized with peroxidase conjugated anti-human IgG and anti-human IgA rabbit antibodies through peroxidase reaction. Lanes 1:pUR288 as negative control; lanes 2: pUCARG1140 as a positive control; lanes 3:pUR540; lanes 4: pUR600. The different $M_{\mathrm{r}}$ s, especially for pUCARG1140, result from different running times of the SDS-PAGE. The main reaction of the IgG and IgA antibodies in NPC serum No. 352 is directed against the fusion protein encoded by pUR540 with the antigenic region from the C-terminus of ep138 (FR.VII). In serum No. 354 the majority of the antibodies recognizes the antigenic site encoded by pUR600 (FR.IV), indicating that both protein segments are necessary for detecting all anti-ep138 antibodies in sera.

pool prepared from many sera of NPC patients did not detect additional antigenic sites (Fig. 5). These data imply that both antigenic sites are necessary and sufficient to obtain the desired specificity in the ELISA usable for diagnostic purpose.

A partially purified preparation of the PUCARG1140 -encoded protein was used to immunize rabbits. The resulting antiserum was tested in an immunoprecipitation with $\left[{ }^{35} \mathrm{~S}\right]$ methionine-labeled induced P3HR1 cell extract (not shown). Only ep138 reacts specifically with the rabbit antiserum, which is further proof for the correct expression of this protein.
Preliminary experiments indicate the value of the pUCARG1140-encoded protein as antigen in the diagnostic of EBV-related diseases of NPC (in preparation).

The antigen encoded by pUCARG 1140 is only a first step in generating a complete set of proteins covering all necessary antigens for EBV diagnosis. Beside ep 138, we have expressed another early protein, a VCA protein, a nuclear antigen and the major membrane protein of EBV (in preparation). 


\section{ACKNOWLEDGEMENTS}

The authors would like to thank G. Deby for her devoted technical assistence, Dr. Peter Heinrich for confirming the sequence of the polyArg-coding insert and Dr. Ronald Merz for the synthesis of the polyArg-coding oligodnt. This work was supported by BMFT.

\section{REFERENCES}

Amann, E. and Brosius, J.: 'ATG vectors' for regulated high-level expression of cloncd gencs in Escherichia coli. Gene 40 (1985) 183-190.

Amann, E., Brosius, J. and Ptashne, M.: Vectors bearing a hybrid trp-lac promoter useful for regulated expression of cloned genes in Escherichia coli. Gene 25 (1983) 167-178.

Argos, P., Hanei, M. and Garavito, M.: The Chou-Fasman secondary structure prediction method with an extended data base. FEBS Lett. 93 (1978) 19-24.

Bayliss, G.J. and Wolf, H.: The regulated expression of EpsteinBarr virus. III. Proteins specified by EBV during the lytic cycle. J. Gen, Virol. 56 (1981) 105-118.

Baer, R., Bankier, A.T., Biggin, M.D., Deininger, P.L., Farrell, P.J., Gibson, T.J., Hatfull, G., Hudson, G.S., Satchwell, S.C., Seguin, C., Tuffnell, P.S. and Barrell, B.G.: DNA sequence and expression of the B95-8 Epstein-Barr virus genome. Nature 310 (1984) 207-211.

Burnette, W.N.: 'Western blotting': electrophoretic transfer of proteins from sodium dodecyl sulfate-polyacrylamide gel to unmodified nitrocellulose and radiographic detection with antibody and radioiodinated protein A. Analyt. Biochem. 112 (1981) 195-203.

Chou, P.Y. and Fasman, G.D.: Conformational parameters for amino acids in helical, $\beta$-sheet, and random coil regions calculated from proteins. Biochemistry 13 (1974a) 211-222.

Chou, P.Y. and Fasman, G.D.: Prediction of protein conformation. Biochemistry 13 (1974b) 222-245.

Cohen, G.H., Dietzschold, B., Ponce de Leon, M., Long, D., Golub, E., Varrichio, A., Pereira, L. and Eisenberg, R.J.: Localization and synthesis of an antigenic determinant of Herpes simplex virus glycoprotein D that stimulates the production of neutralizing antibody. J. Virol. 49 (1984) 102-108.

DeBoer, H.A., Comstock, L.J. and Vasser, M.: The tac promoter: a functional hybrid derived from the trp and lac promoters. Proc. Natl. Acad. Sci. USA 80 (1983) 21-25.

Denhardt, D.T.: A membrane-filter technique for the detection of complementary DNA. Biochem. Biophys. Res. Commun. 23 (1966) 641-646.

Devereux, J., Haeberli, P. and Smithies, O.: A comprehensive set of sequence analysis programs for the VAX. Nucl. Acids Res. 12 (1984) 387-395.

Guise, K.S., Korneluk, R.G., Waye, J., Lamhonwah, A.-M., Quan, F., Palmer, R., Ganschow, R.E., Sly, W.S. and Gravel, R.A.: Isolation and expression in Escherichia coli of a cDNA clone encoding human $\beta$-glucuronidase. Gene 34 (1985) 105-110.

Hogle, J.M., Chow, M. and Filman, D.J.: Three-dimensional structure of polio-virus at 2.9 Ångstrom resolution. Science 229 (1985) 1358-1363.

Hopp, T.P. and Woods, K.R.: Prediction of protein antigenic determinants from amino acid sequences. Proc. Natl. Acad. Sci. USA 78 (1981) 3824-3828.

Jameson, B.A., Emini, E.A. and Wimmer, E.: Analysis of neutralization structures on poliovirus type 1 and the neutralizing antibody response to synthetic peptides. In Bell, R. and Torrigiani, G. (Eds.), New Approaches to Vaccine Development. Schwabe, Basel, Switzerland, 1984, pp. $237-252$.

Laemmli, U.K.: Cleavage of structural proteins during the assembly of the head of bacteriophage T4. Nature 227 (1970) $680-685$.

Masui, Y., Mizuno, T. and Inouye, M.: Novel high-level expression cloning vehicles: $10^{4}$-fold amplification of Escherichia coli minor protein. Bio/Technology 2 (1984) 81-85.

Pearson, R.E., Bejcek, B. and Conley, A.J.: A physical domain of Herpes simplex virus ICP8 is expressed and active in Escherichia coli. J. Virol. 53 (1985) 360-365.

Roubal, J., Kallin, B., Luca, J. and Klein, G.: Early DNA-binding polypeptides of Epstein-Barr virus. Virology 113 (1981) 285-292.

Rüther, U. and Müller-IIll, B.: Easy identification of cDNA clones. EMBO J. 2 (1983) 1791-1794.

Sassenfeld, H.M. and Brewer, S.J.: A polypeptide fusion designed for the purification of recombinant proteins. Bio/Technology 2 (1984) 76-81.

Scibl, R. and Wolf, H.: Mapping of Epstein-Barr virus proteins on the genome by translation of hybrid-selected RNA from induced P3HR 1 cells and induced Raji cells. Virology 141 (1985) $1-13$.

Simons, M.J. and Shanmugaratnam, K. (Eds.): The Biology of Nasopharyngeal Carcinoma. UICC Technical Report, 71, Geneva, Switzerland, 1982.

Skare, J. and Strominger, J.L.: Cloning and mapping of Bam HI endonuclease fragments of DNA from the transforming B958 strain of Epstein-Barr virus. Proc. Natl. Acad. Sci. USA 77 (1980) 3860-3864.

Vieira, J. and Messing, J.: The pUC plasmids, a M13mp7-derived system for insertion mutagenesis and sequencing with synthetic universal primers. Gene 19 (1982) 259-268.

Wolf, H., Motz, M., Kühbeck, R., Seibl, R., Jilg, W. Bayliss, G.J., Barrell, B., Golub, E., Zeng, Y. and Gu, S.-Y.: Strategies for the economic preparation of Epstein-Barr virus proteins of diagnostic and protective value by genetic engineering: a new approach based on segments of virus-encoded gene products. In Williams, A.O., O'Conor, G.T., de-The, G.B. and Johnson, C.A. (Eds.), Virus-associated Cancers in Africa. IARC Sci. Publ., Lyon, France, 1984, pp. 525-539.

Yanisch-Perron, C., Vieira, J. and Messing. J.: Improved M13 phage cloning vectors and host strains: nucleotide sequences of M13mp 18 and pUC19 vectors. Gene 33 (1985) 103-119.

Zeng, J.: Seroepidemiological studies on nasopharyngeal carcinoma in China. Adv. Cancer Res. 44 (1985) 121-136. 